\title{
Potential uses of natural zeolites for the development of new materials: short review
}

\author{
V. Petranovskii ${ }^{1}$, F. Chaves-Rivas ${ }^{2}$, M.A. Hernandez Espinoza ${ }^{3}$, A. Pestryakov ${ }^{4 *}$, E. Kolobova ${ }^{4}$ \\ ${ }^{1} \mathrm{CNyN}$, Universidad Nacional Autonoma de Mexico, Ensenada, 22800, Mexico \\ ${ }^{2}$ Instituto Politechnico Nacional, Mexico Distrito Federal, 07738, Mexico \\ ${ }^{3}$ Benemerita Universidad Autonoma de Puebla, Puebla 72570, Mexico \\ ${ }^{4}$ Tomsk Polytechnic University, Tomsk, 63450, Russia
}

\begin{abstract}
Zeolites stand apart among the many families of porous materials. Due to their structure, they have a number of important practical properties such as a high adsorption capacity and the ability to cation exchange. However, the main feature distinguishing them from other porous bodies and inherent only for zeolites is the ordering of the pores in their size, orientation, and mutual locations. Pore diameters for the crystalline structures of various zeolites may vary from 0.25 to about 15 nanometers. The crystalline arrangement of these pores in space converts zeolites in the naturally existing nanostructured materials, possessing the unique property to present ordered location of stabilized nanoparticles.
\end{abstract}

\section{Introduction}

Since the last millennium, zeolites are known as a "magic rock" [1]. The search for methods of synthesis of nanoparticles, investigation of their unique properties, and development of new materials for exploring these properties for applications in advanced technology have undoubted value. Clearly, nanoparticles with sizes in range of a few nanometers can be applied in industrial processes only if supported on solid matrices. Such matrix must be inert in the environment, where the prepared materials are applied. Fortunately, such matrices are created by nature; which are natural zeolites, with a structure possessing channels and cavities of nanometric size, and relatively stable.

In countries such as Cuba, Japan and the USA, many studies have been conducted that have led to new and innovative applications of natural zeolites [1-4]. Other countries, such as Mexico and Russia, where zeolites are found in abundance, have the potential to become an industry leader of zeolitic materials. Innovative research work is needed to find new ways in which zeolites can be used to benefit people and the environment. The aim of the present paper is to estimate potential use of natural zeolites for production of new industrially and environmentally important materials.

\section{Available reserves of zeolites}

\subsection{Estimates of World reserves}

Although, there are no certain figures on the total amount of zeolites in the world, it is well known that they are present on all the continents with varying mineral contents and kinds. World production of natural zeolites was estimated in the year 2004 to be between 2.5 and 3 million metric tons (Mt) based on reported production by some countries [5]. Three years later world production of natural zeolites was estimated to be approximately the same [6]. Last year (2015) situation [7] is shown in Figure 1.

\subsection{Availability of natural zeolites in Russia}

Less than ten deposits are exploited at present in Russia, between others the Holinsk deposit (clinoptilolite) and Mukhor-Tala deposit (mordenite) in the Republic of Buryatia, and "Priargunskoe" Mining and Chemical Association [8]. Evaluation of the Mukhor-Tala deposit was reported in Ref. [9]. Such a small amount of produced zeolite (between

\footnotetext{
${ }^{*}$ Corresponding author: pestryakov2005@yandex.ru
} 
3000 and $5000 \mathrm{t}$ for all countries of Russian Commonwealth) contradicts to huge reserves of known deposits, and mainly is due to the few researches dedicated to the use of natural zeolites in industry and agriculture.

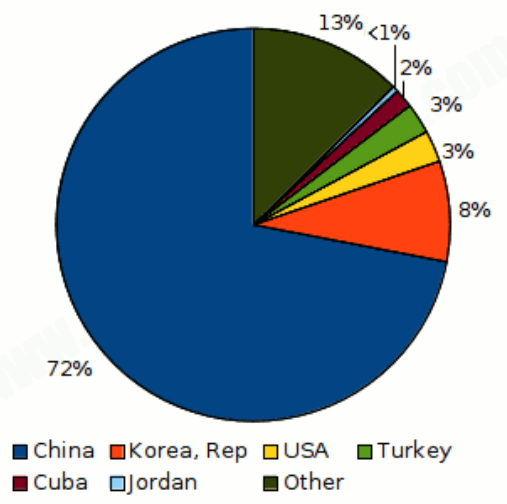

Fig. 1. Where do natural zeolites come from? Estimated world mine production for 2015. China produced almost three quarters of all natural zeolites (2 million tons) [7]. Total world reserves of zeolites are unknown "but are estimated to be large" [7].

\section{Zeolites}

Zeolites are the aluminosilicate members of the family of microporous solids known as "molecular sieves" (Figure 2). Due to isomorphous substitution of $\mathrm{Si}^{4+}$ by $\mathrm{Al}^{3+}$, the zeolite framework get a negative charge and so, need for any cations; those are not the structural units of their crystalline structure, but serve to neutralize the charge of framework only. These charge carriers are located in the voids of zeolite structure, and can easily be exchanged for any other ions.

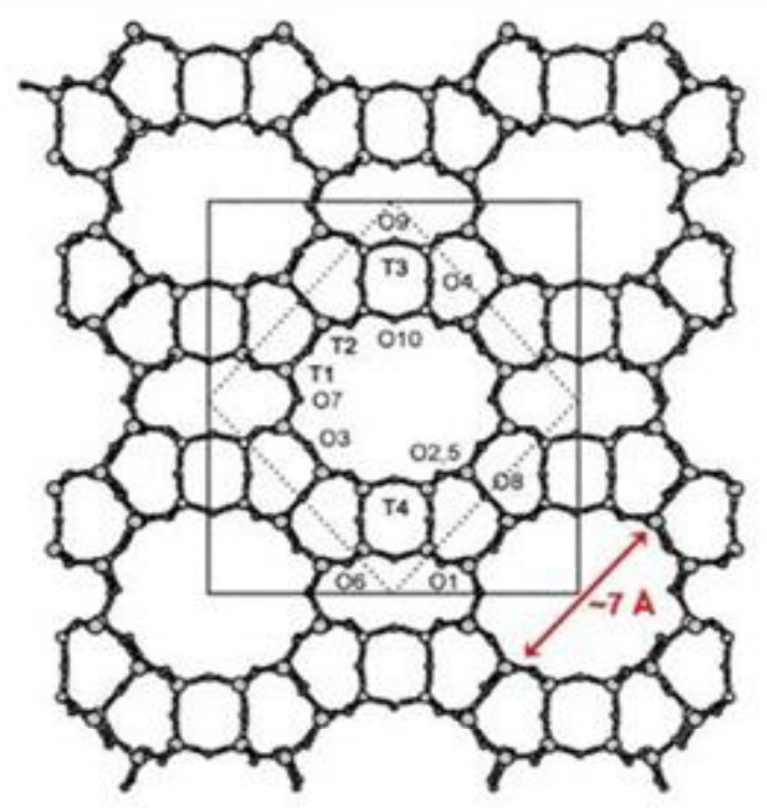

Fig. 2. Projection of mordenite framework along the $c$ axis, presenting a view along the channel (twelve-membered ring) and shoving also the side pockets (eight-membered rings). The four inequivalent tetrahedral sites labeled $\mathrm{T} 1$ to $\mathrm{T} 4(\mathrm{~T}=\mathrm{Si}$ or $\mathrm{Al})$ are shown by the larger light grey spheres. Oxygen atoms are represented by smaller dark spheres and numbered O1 to O10. The solid frame shows the conventional centrosymmetric orthorhombic unit cell, the dashed frame - the primitive unit cell (adapted from Ref. [24]). 
The ion exchange property is one of the main features that zeolites exhibit (both natural and synthetic ones). This feature is important from two points of view. First, cations introduced in zeolite matrices by ion exchange treatment allow subsequent development of materials for catalytic, medical and antibacterial applications, between many others [10-17]. Secondly, one of the most important applications is the processes of removing of pollutants such as heavy metals from the wastewater of industrial plants, soil, and other sources [18-23]. Chip and abundant natural zeolites are very suitable material for harmful ions removal, because polymetallic cation mixture inherent to natural zeolitic rock, mineral impurities, and as a rule several zeolitic phases presenting in the row natural mineral do not hinder their use for accumulation of undesired cations in the ambient.

Cation exchange properties are very important applications, for example in environment protection to trap radioactive cations. It is well known that after Chernobyl catastrophe "permeable reactive barriers" made from natural zeolites, especially from clinoptilolites [25] were applied to prevent diffusion of the radionuclides [26,27].

Similar methods were used to tolerate Fukushima nuclear contamination. The Japanese government hopes that the zeolites help reduce radioactive contamination of the sea. Availability and reasonable cost of natural clinoptilolite together with its high selectivity towards $\mathrm{Sr}^{2+}$ and $\mathrm{Cs}^{+}$radionuclides make possible the use of a clinoptilolite tuff as a barrier. The potential use of natural zeolites as cation exchangers in environmental protection include scavenging of fall-out products from living hosts [27], ammonium removal from municipal sewage [18], desalination treatment of sea water [28], or remediation of hazardous heavy metal-polluted soils [29] or sediments [30].

\subsection{Future applications of zeolites}

All of the above-mentioned applications of zeolites are based on the fact what they are naturally existing nanostructured materials. Advances of modern preparative chemistry and materials engineering allow improving existing materials, and to give them new properties. Two main features of zeolites allow synthesize on their base new modern materials - their regular pore structure (Fig. 2) and ion exchange properties. The processes that include formation of complex-cations on zeolites are important to develop industrially significant materials, such as catalysts [10-12] and photocatalysts [13], medicine [14], sensor materials [31,32], feeding additives for farm animals [33], etc.

\subsection{Nanozeolites}

Very interesting question also arises in connection with the size of the zeolite particles. All known applications were developed while applying zeolites in the regular granulometric scale. What happens if this natural nanostructured material will be prepared in the form of nanoparticles?

Recently, the methods of nanozeolite synthesis were developed [34,35]. Nanozeolites are a type of zeolites, which have narrow particle size distribution with sizes of less than $200 \mathrm{~nm}$ [36]. Compared to "ordinary" zeolites of which the particle diameters are of micrometer order, nanozeolites represent very small particle size, and especially, the fact that they are composed of discrete particles (single crystals) rather than aggregates.

One of the advantages of nanozeolites is their extremely high external surface area. The external surface is of vital importance in numerous processes, including adsorption and catalysis. For example, in the fluidized catalytic cracking (FCC) process, the commercial catalysts are manufactured by dispersion of micron-sized zeolites in an amorphous alumina-silica matrix. For cracking to occur, gas oil molecules must pass through the matrix and reach the surface of the zeolite crystals. The molecules then diffuse through the micropores of $Y$ zeolites until they reach an active site. Due to the zeolite structure, molecules larger than $7.4 \AA$ cannot reach active sites located inside the mordenite. This problem can be avoided by replacing the micrometer-sized zeolites with the corresponding nanozeolites. The substitution could lead to a decrease in the diffusional resistance and an increase in the external surface area, hence raising the number of active sites available for large molecules.

\subsection{Potential applications of nano-zeolites}

Zeolite particles in the 10-100 $\mathrm{nm}$ range can bring in new applications of zeolites. The huge surface areas of the nanosized materials dictate that many of the atoms are on the surface, thus allowing good "atom economy" in surfacegas and surface-liquid interface. The ratio of atoms available on the surface increases as the crystal size decreases.

Such phenomenon can be responsible for the observation that clinoptilolite powder can be used as a potential adjuvant in anticancer therapy [37]. It was shown, that anticancer activity of natural clinoptilolite significantly increased after fine milling. Better results were observed if the zeolite used for medical purposes was processed by a special micronization machine that increased the surface area several times over, and ground the material into various sized particles, with about $15 \%$ being nanoparticles as small as $100 \mathrm{~nm}$ [38]. Many other medical applications of zeolites are actively being explored [39].

\section{Hybrid materials based on zeolites}


Another method of creating hybrid materials composed of nanoparticles deposited on nanostructured supports also exploits the ion exchange properties of zeolites. In recent years, zeolites have gained importance for their capacity to accommodate clusters of other materials in their void space (regular channels and cavities, as well as irregular mesoporosity existing due to defects of crystalline structure) and on the surface. This facility to insert clusters allows one to create new composites with desirable properties for photocatalysis.

\subsection{Intra-zeolite chemistry}

General formula of zeolite is $\left(\mathrm{M}^{+1}\right)_{\mathrm{x}}\left[\mathrm{Al}_{\mathrm{x}} \mathrm{Si}_{\mathrm{y}} \mathrm{O}_{2(\mathrm{x}+\mathrm{y})}\right]$, where $\mathrm{M}^{+1}$ usually is $\mathrm{Na}^{+1}$ ion. These $\mathrm{Na}^{+1}$ ions can be exchanged for any other ions, for example $\mathrm{Ag}^{+}, \mathrm{Cd}^{2+}, \mathrm{Zn}^{2+}, \mathrm{Cu}^{2+}$, etc. After that, $\mathrm{Ag}^{+}$can be reduced, forming $\mathrm{Ag}^{0}$. Reduced silver atoms can agglomerate inside the cavity, forming small clusters, according to the reaction $\mathrm{nAg}^{0}=\mathrm{Ag}_{\mathrm{n}}$. Similar processes take place with other exchanged transition metal ions [11,40,41].

Another possibility is to realize chemical reactions inside of nano-voids of zeolite structure. Silver ions $\mathrm{Ag}^{+}$can react with $\mathrm{NaBr}$ solution, precipitating $\mathrm{AgBr}$ nanoparticles:

$$
\mathrm{Ag}[\text { Zeolite }]+\mathrm{NaBr}=\mathrm{AgBr} @ \mathrm{Na}[\text { Zeolite }]
$$

Where symbol "@)" means "localized inside of zeolite porosity".

If solutions containing $\mathrm{S}^{2-}$ anions will be used, $\mathrm{CdS}$ or $\mathrm{ZnS}$ sulfides dispersed inside of zeolite cavities can be obtained $[13,42,43]$. In these works, ion exchange by hydrothermal technique was used to synthesize the composites. Nanoclusters with a broad size distribution were formed inside the channels and on the external surface.

\subsection{Confinement of nanoparticles in zeolite nanoporosity}

New nanostructured materials will provide new interesting physical properties, which are characteristic of electron confinement in curved space with $3 \mathrm{D}$ periodicity [44]. Semiconductor nanoparticles exhibit quantum confinement effects when their dimensions become as small as or smaller than the Bohr radius. This quantum confinement causes drastic changes in the electronic and physicochemical properties of the semiconductor-zeolite composites [45-47]. Due to transparency of zeolites in the UV-Vis range, the zeolites can serve as inert supports for the photocatalytically active semiconductors.

Schematically, such a material consisting of nanoparticles deposited on nanostructured carrier is shown in Figure 3. As an example, erionite framework (A) is selected. After chemical reactions, nanoparticles (balls in B (side view) and C (projection view) parts of Fig. 3) are stabilized inside of erionite cavities.

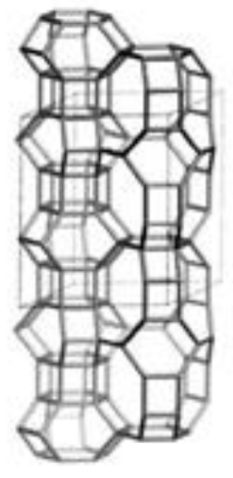

A

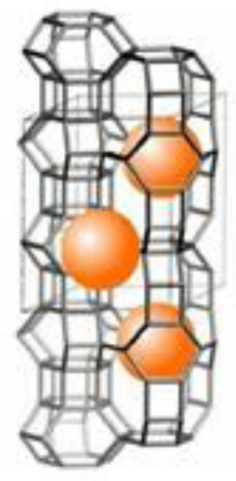

B

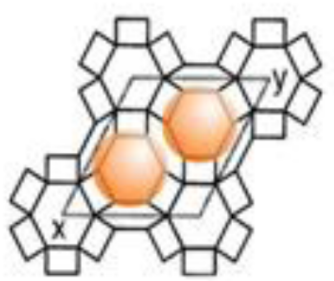

C

Fig. 3. Schematically represented framework of erionite channels (A), and metal clusters shown as a bolls. Dash frames show the conventional unit cell.

\section{Concluding Remarks}

Zeolites represent a class of well-known minerals and materials with a high potential for industrial utilization. Classical fields are detergent additives, catalysts in cracking processes of the petroleum refining industry and as molecular sieves in environmental applications, soil improvement and nuclear waste treatment. Recent innovative applications of zeolites regard their use as host matrices for a large variety of guests. These hybrid materials can be exploited in several research fields, as devices for solar energy harvesting, processing/storing of information, and advanced sensing technology for analytics and diagnostics on the nanoscale. Many microporous heteropolyhedral compounds, containing metals such as Mo, V, Sn, Zr, Ti, Ca and lanthanides, with a wide number of distinct structural types, have been reported and their potential applications in the areas of catalysis, separation of molecular species, ion exchange and optical and magnetic devices have been evaluated. We expect contributions on mineralogy, structure, P-T stability, 
crystal-chemistry and applications of natural and related synthetic porous phases, and hence from mineralogy and petrology researchers as well as from crystallographers and material scientists.

\section{Acknowledgments}

This research was supported by Russian Government Program «Science» of Tomsk Polytechnic University, grant No. 4.1187.2014/K. F.C.R. acknowledge support from COFAA and PIFI-IPN.

\section{References}

1. F.A. Mumpton, Geology, Mineralogy, and Human Welfare: Proc. of the National Academic of Science of the USA colloquim 96, 3463 (1999)

2. T. Selvam, W. Schwieger, W. Dathe, Clay Miner. 49, 501 (2014)

3. V.J. Inglezakis, A.A. Zorpas, Handbook of natural zeolites (Potomac: Bentham Books) (2012)

4. C. Laurino, B. Palmieri, Nutr. Hosp. 32, 573 (2015)

5. Virta R.L. Zeolites Minerals Year Book (Reston, VA: USGS) 83.1-83.3 (2004)

6. Virta R.L. Zeolites Minerals Year Book (Reston, VA: USGS) 83.1-83.3 (2007)

7. US Geological Survey: Mineral Commodity Summaries: Zeolites (Natural), January 2016. http://minerals.usgs.gov/minerals/pubs/commodity/zeolites/index.html; Last accessed at May 242016

8. Overview of market of natural zeolites in the Commonwealth of Independent States, INFOMINE Research Group, http://www.infomine.ru/files/catalog/76/file_76_eng.pdf; Last accessed at May 242016

9. V.I. Prihodko, New technologies for production and processing of raw materials in terms of environmental restrictions: Proc. Russian Scientific Conference (Ulan-Ude) 72 (2004)

10. N.M. Xavier, S.D. Lucas, Rauter A.P., J. Mol. Catal. A: Chem. 305, 84 (2009)

11. V. Petranovskii, A. Pestryakov, L. Kazantseva, J. Cruz, A. Kryazhov, Stud. Surf. Sci. Catal. 174, 513 (2008)

12. V. Petranovskii, A. Pestryakov, L. Kazantseva, F.F. Castillon Barraza, M.H. Farias, Int. J. Modern Phys. B 19, 2333 (2005)

13 A. Nezamzadeh-Ejhieh N. Moazzeni, J. Ind. Eng. Chem. 19, 1433 (2013)

14. J. Hrenovic, J. Milenkovic, T. Ivankovic, N. Rajic, J. Hazard. Mater. 201-202, 260 (2012)

15 A.N. Pestryakov, N. Bogdanchikova, A. Simakov, I. Tuzovskaya, F. Jentoft, M. Farias, A. Diaz, Surf. Sci. 601, 3792 (2007)

16. E. Smolentseva, N. Bogdanchikova, A. Simakov, A. Pestryakov, M. Avalos, M.H. Farias, A. Tompos V. Gurin, J. Nanosci. Nanotechnol. 7, 1882 (2007)

17. A. Pestryakov, I. Tuzovskaya, E. Smolentseva, N. Bogdanchikova, F. Jentoft, A. Knop-Gericke, Int. J. Modern Phys. B 19, 2321 (2005)

18. C. Colella, Natural microporous materials in environmental technology: Proc. NATO Advanced Research Workgroup (NATO Advanced Study Institute, Series E: Applied Sciences vol 362) (Boston: Kluwer Academic Publishers) 207 (1999)

19. X. Wanjing, Y.L. Loretta, J.R. Grace, G. Hébrard, Appl. Clay Sci. 80-81, 31 (2013)

20. M.K. Doula, K. Elaiopoulos, V.A. Kavvadias, V. Mavraganis, J. Hazard. Mater. 207-208, 103 (2012)

21. G.S. Sultanbayeva, R. Holze, R.M. Chernyakova, Micropor. Mesopor. Mat. 170, 173 (2013)

22. S. Babel, T.A. Kurniawan, J. Hazard. Mater. 97, 219 (2003)

23. A. Nezamzadeh-Ejhieh, M. Kabiri-Samani, J. Hazard. Mater. 260, 339 (2013)

24. T. Demuth, J. Hafner, L. Benco, H. Toulhoat, J. Phys. Chem. B 104, 4593 (2000)

25. V. Nikashina, I. Serova, E. Kats, N.A. Tikhonov, M.G. Tokmachev, Clay Miner. 46, 233 (2011)

26. A. Nesterenko, V. Nesterenko, A.Yablokov, Ann. NY Acad. Sci. 1181, 287 (2009)

27. A. Dyer, Environmental mineralogy: Microbial interactions, anthropogenic influences, contaminated land and waste management: Proc. Mineralogical Society's winter meeting (London: Mineralogical Society) 319 (2000)

28. T. Wajima, Anal. Sci. 29, 139 (2013)

29. W.Y. Shi, H.B. Shao, H. Li, M.A. Shao, J. Hazard. Mater. 170, 1 (2009)

30. Y. Chiang, R.M. Santos, K. Ghyselbrecht, V. Cappuyns, J.A. Martens, R. Swennen, T. Van Gerven, B.Meesschaert, J. Environ. Manage 105 (2012)

31. Y.G. Zheng, X.G. Li, Sensors 12, 5170 (2012)

32. O.Y. Saiapina, V. Pyeshkova, O. Soldatkin, V. Melnik, B. Akata Kurç, A. Walcarius, N. Dzyadych Jaffrezic-Renault, Mat. Sci. Eng. C 31, 1490 (2011)

33. L. Nimatsyrenova S. Zhamsaranova, Bull. Buryat State Agricultural Acad. V.R. Filippov 4, 106 (2011)

34. D. Karami, S. Rohani, Rev. Chem. Eng. 23, 1 (2007)

35. T. Tago, T. Masuda, Nanocrystals (Sciyo: [S.I.]) 191 (2010)

36. L. Tosheva, V.P. Valchev, Chem. Mater. 17, 2494 (2005)

37. K. Pavelić, M. Hadzija, L. Bedrica, J. Pavelić, I. Dikić, M. Katić, M. Kralj, M.H. Bosnar, S. Kapitanović, M. Poljak-Blazi, S. Krizanac, R. Stojković, B. Subotić , M. Colić, J. Mol. Med. 78, 708 (2001)

38. N. Zarkovic, K. Zarkovic, M. Kralj, S. Borovic, S. Sabolovic, M.P. Blazi, A. Cipak, K. Pavelic, Anticancer Res. 23, 1589 (2003)

39. S.M. Auerbach, K. Carrado, P.K. Dutta, Handbook of zeolite science and technology (New York: M. Dekker) 1184 (2003)

40. Yu. A. Alekseev, V.N. Bogomolov, T.B. Zhukova, V.P. Petranovskii, S.G. Romanov, S.V. Kholodkevich, Bull. Acad. Sci. USSR Phys. Series 50, 1 (1986)

41. Y. Meteleva, F. Roessner, G.F. Novikov, J. Photochem. Photobiol. Chem. A 196, 154 (2008)

42. M.S. Sadjadi, A. Pourahmad, S. Sohrabnezhad, K. Zare, Mater. Lett. 61, 2923 (2007)

43. O. Jaime-Acuña, H. Villavicencio, J. Díaz-Hernández, V. Petranovskii, M. Herrera, O. Raymond, Chem. Mater. 26, 6152 (2014)

44. J. Cejka, H. Bekkum, A. Corma, F. Schueth, Introduction to zeolite molecular sieves $\left(3^{\text {rd }}\right.$ ed. Studies in Surface Science and Catalysis vol. 168) (Amsterdam: Elsevier) 800 (2007)

45. F. Iacomi, Surf. Sci. 532-535, 816 (2003)

46. P.V. Kamat, J. Phys. Chem. C 111, 2834 (2007)

47. P.V. Kamat, J. Phys. Chem. C 112, 18737 (2008) 